ISSN 2392-4896 (online)

ISSN 2392-4888 (print)

Journal of Management and Development Studies Vol. 27:pp.1-15

Available online http://nasc.org.np

(c)2016Nepal Administrative Staff College

\title{
Notes on Bhutan's Gross National Happiness and its Measurement
}

\author{
Edoardo Monaco \\ Hong Kong Baptist University \& Beijing Normal University, United International \\ College (UIC), Zhuhai, Guangdong Province, China \\ Email: emonaco@uic.edu.hk
}

Accepted: 15 April 2016

Bhutan, a Himalayan landlocked country of just about 750,000 inhabitants, has since the 1980s adopted a unique, holistic approach to development governance commonly referred to as 'Gross National Happiness' (GNH), which aims at achieving equitable socio-economic progress in harmony with other fundamental 'pillars' such as environmental preservation, good governance, and protection of the local cultural identity. The strategy - inspired, above all, by solid Tantric Buddhist belief - significantly differentiates itself from the mainstream GDP-driven, output-maximizing paradigms by maintaining that truly sustainable development can only originate from acknowledging the equal dignity and crucial interdependence of various dimensions of both human and natural life. This paper, drafted in the month of December 2015, briefly analyzes GNH policy's key tenets and achievements - more conspicuous in regards to democratic governance and environment than in terms of inclusive, multidimensional poverty reduction, as well as its recently devised measuring tool, the GNH Index, and the results of its latest surveys. Factors like the peculiar Buddhist culture that informs it, the relatively simple economic infrastructure at this early stage of development, as well as the limited size of the politically active, urbanized population, all make GNH per se a distinctively Bhutanese phenomenon. Nevertheless, the fundamental paradigm shift that GNH advocates has already resonated beyond the countries' borders, reinforcing a growing trend across international development actors towards a more comprehensive, qualitative definition and measurement of societal development.

Keywords: development, wellbeing, sustainability, multidimensional approach, gross national happiness

\section{A development geography hotspot}

Despite an average per capita Gross Domestic Product (GDP) of 2,560 USD in 2014 (World Bank, 2015a), a consistent presence in the UN's list for Least Developed 
Countries (United Nations [UN], 2015) and a ranking as $132^{\text {nd }}$ in the latest Human Development Report (United Nations Development Programme [UNDP], 2015), Bhutan - a small Himalayan nation of barely 750,000 inhabitants, sandwiched between China and India - has often been considered an important benchmark by modern development strategists. This owes certainly to the significant reduction in the levels of income poverty registered in the country (World Bank, 2015b), slowly but steadily, in the last two decades - thanks mainly to the performance of the main revenue-earning sector, i.e. export of hydropower, and, to a lesser extent, the tourism industry - but even more so to a peculiar development paradigm emerged from the early 1970s onwards. It was then, in fact, that Jigme Singye Wangchuck, young $4^{\text {th }}$ King of the Wangchuck dynasty $^{1}$, spoke for the first time about the need for his administration to pursue not just mere GDP growth, but the general increase of 'Gross National Happiness' (GNH) instead.

Over the years, the king's words grew - especially throughout the 1990s and early 2000s - from 'raw intuition' into a structured, overarching development paradigm of constitutional relevance (Constitution of the Kingdom of Bhutan, 2008), as well as into a pivot of national conscience and a possible model for other nations across the world.

\section{Defining Bhutan's holistic wellbeing}

The term 'happiness', in this context, should not be interpreted as subjective, emotional state of mind, but more broadly as both individual and collective citizens' wellbeing.

The policy is in fact based on a holistic concept of development, intended as a sustainable, equitable, comprehensive improvement of social wellbeing in all of its various dimensions, i.e. material, spiritual, social, political, and environmental. No single dimension should be privileged to the detriment of another, and no short-term achievement pursued to the detriment of future generations.

The influence of the nationally prevalent Vajrayana Tantric Buddhist principles and Bon animist beliefs that preceded them, is evident, as GNH reflects the multidimensional nature of human life and acknowledges the crucially interdependent, equally relevant roles played by various factors contributing to universal harmony.

$\mathrm{GNH}$, in this sense rejects the mono-dimensionality of GDP-centered development approaches: GDP is a quantitative measure of mere economic output, unable to take into consideration the 'quality' of the output itself, ignoring key non-

\footnotetext{
${ }^{1}$ The first to unify under one rule a previously fragmented, formally independent country, in 1907.
} 
market components of wellbeing for the simple reason that they traditionally elude immediate estimation. Hence, GDP-centered development governance would inevitably deliver partial results in terms of promotion of broader wellbeing, and lack a proper measure to gauge its policies' progress in this sense.

As a holistic approach, GNH has grown through the years to include four pillars ${ }^{2}$ : good governance; sustainable and equitable socio-economic development; conservation and sustainable utilization of natural environment; cultural preservation and promotion.

Specific policies in each of the above mentioned four dimensions have been measured against the yardstick of the GNH principles, especially since their inclusion in the first democratic constitution of 2008 (Constitution of the Kingdom of Bhutan, $2008)^{3}$, and the consequent establishment of the Gross National Happiness Commission (GNHC). GNHC is entrusted with the fundamental duty to 'direct and coordinate the formulation of all policies, plans and programmes in the country and ensure that GNH is mainstreamed into the planning, policymaking and implementation process by evaluating their relevance to the GNH framework' (Gross National Happiness Commission, accessed in 2015). In cooperation with the Centre for Bhutan Studies and GNH Research, GNHC also monitors all policy results through surveys and related use of the GNH Index.

De facto, this has defined GNH as both the ends and the very means through which development shall be promoted in the country. It is not only the ultimate goal of governance, but also the inspiring force, the matrix behind every other policy, and a paradigm the whole governance system has to be constantly measured against.

\section{Overview of macro-achievements in the 'pillar areas'}

Good governance has been successfully pursued through means of democratization, decentralization, promotion of political awareness and institutionalization of GNH. The democratization process culminated in the adoption of the 2008 Constitution that marked the shift from absolute to constitutional monarchy, and the first parliamentary elections of $2008^{4}$. Power devolution meant division in 20 administrative districts

\footnotetext{
${ }^{2}$ Further broken down, for measuring purposes, into nine so-called "domains".

${ }^{3}$ In particular article 9.2 of the Constitution reading: "The State shall strive to promote those conditions that will enable the pursuit of Gross National Happiness."

${ }^{4}$ Won by Bhutan Peace and Prosperity Party (Druk Phuensum Tshogpa, or DPT), led by Jigme Yoser Thinley, Prime Minister in the period 2008-2013. Following elections, in 2013, were won by the former opposition, the People's Democratic Party (PDP), led by Tsering Tobgay (incumbent Prime Minister).
} 
(dzongkhags) and some 205 sub-district units called 'gewogs', i.e. groups of few villages headed by an elected representative, or 'gup'. The structuring of GNH implementation procedures has occurred mainly through the creation of the above mentioned GNH Commission in place of the former Planning Commission and Committee of Secretaries, as a quasi-executive technical commission comprising of Prime Minister, Cabinet Secretary, ten representatives from relevant ministries, and a representative from the National Environmental Commission.

The endeavors in the realm of sustainable and equitable socio-economic development have produced more mixed results. While income poverty decreased significantly from 32 percent in 2003 to 12 percent in 2013, there is still great disparity between rural (16.7\%) and urban areas (1.8\%) and across districts. Moreover, Multidimensional Poverty still stands at 27 percent (UNDP, 2015) ${ }^{5}$.

The Bhutanese economy is planned, on the basis of Five Year Plans (FYPs). The current $11^{\text {th }}$ FYP focuses on three main areas: promoting inclusive growth, development of green economy, and strategic infrastructure. Intervention in these areas aims at tackling challenges such as uneven achievements across districts and ruralurban divide, the need to overcome dependency from aid, imports and hydropower export revenues, as well as youth unemployment ${ }^{6}$. In this context, the 'RISE' plan (Rapid Investment in Selected Enterprises Initiative) intends to focus on enhancing capacity in food processing, tourism, cottage industry and manufacturing in the short term. World Trade Organization (WTO) membership, thoroughly debated in the past few years, has been officially put on hold. The membership to the organization, although acknowledged as a potential short-term booster of financial gains, has been in fact deemed as a substantial long-term threat to the 'sovereign', independent implementation of GNH policy tenets in the country. Bhutan remains in the UN list of

\footnotetext{
${ }^{5}$ A measure of poverty developed by Sabina Alkire and James Foster at the Oxford Poverty and Human Development Initiative, Oxford University, and based on the same "multidimensional methodology" which GNH Index itself relies upon, redefining poverty as weighed average deprivation across ten indicators (i.e. years of schooling, school attendance, child mortality, nutrition, cooking fuel, sanitation, drinking water, electricity, flooring, asset ownership) within the same three domains as the Human Development Index, i.e. education, health and living standards. (Oxford Poverty and Human Development Initiative, Oxford University, http://www.ophi.org.uk/, accessed in December 2015)

${ }^{6}$ In this regard, it is particularly interesting to note the concern of the authorities for the "quality" of employment, as in 2012 about half the employed population was illiterate or earning less than 5000 Ngultrums (about 75USD), despite rather encouraging crude statistics speaking of a relatively low overall unemployment: 2.6 percent in 2014, down from 2.9 percent in 2013; youth unemployment rate down to 9.4 percent in 2014 from 9.6 percent in 2013 (Gross National Happiness Commission, 2013; Ministry of Labor and Human Resources, Government of Bhutan, 2014).
} 
Least Developed Countries, which does, currently offer benefits in the form of lower tariff-barriers to export into developed countries. Said benefits, though, are yet to be fully tapped into due to limited exports available in the first place, significant non-tariff barriers, and the fact that most of Bhutan current exports end into neighboring countries with which preferential agreements are already in place.

Conservation and sustainable utilization of the natural environment have been distinctively successful. Considering the small population, the early stage of industrialization, the limited use of cars ${ }^{7}$ and the availability of hydropower, Bhutan is a carbon negative country, $70 \%$ of which is covered in forests. About half of the national territory constitutes protected areas. Forests that are not protected are harvested through 'Forest Management Units' for wood and non-wood resources according to the principles of sustained yield. To avoid 'tragedies of commons' and thus allow local subsistence farmers to sustainably preserve the crucial agriculturelivestock-forestry linkage by sharing both benefits and responsibilities related to forest assets, small groups of households can be allocated the joint quasi-ownership of portions of forests on the basis of 'Community Forest Management Groups'. Currently, more than 20,000 households depend on this scheme, and about 600 such groups are active in the country (Ministry of Agriculture, Government of Bhutan, 2015)

Cultural preservation and promotion have been pursued with great fervor, especially from the 1980s onwards. Despite its small population, Bhutan is rather diverse, with Ngalops, Sarchops and Nepalese being the main ethnic groups. Over the course of the $20^{\text {th }}$ century, the Ngalops, together with the Sarchops, became dominant, asserting the Buddhist, Dzonghkha-speaking identity over the Nepalese minority. National codes of etiquette (e.g. 'Driglam Namzha') were adopted in the late 1980s, and were perceived by many Nepalese as measures of forced assimilation. Conflict and tensions ensued, to a point when many Bhutanese of Nepali origin (a number close to 100,000) were ultimately denied citizenship and/or right of abode, determining a refugee crisis that, to this day, still remains partially unresolved (United Nations High Commission for Refugees, 2015). Measures of intense - if not draconian - cultural promotion and preservation seem to have been be driven by an omnipresent 'existential threat syndrome', prompting an objectively fragile identity to protect itself from possible extinction with any available tool. Within this context, GNH as a whole has also served as an aggregating force, promoting a sentiment of nationhood in an ethnically and socio-economically fragmented population, unevenly scattered across distant valleys.

${ }^{7}$ According to World Bank data from 2009, they are 57 per 1000 inhabitants (World Bank, 2009). 
Notes on Bhutan’s Gross National Happiness and its Measurement

\section{Measuring wellbeing: a traditionally challenging pursuit}

Traditionally, measuring wellbeing has proven itself to be a rather challenging pursuit, but nonetheless worthwhile, as societies do measure what they pursue, but also inevitably end up pursuing what they measure. Some, like Jeremy Bentham in the late 1700 s, tried to quantify even the most 'subjective' of its connotations, conceiving an algorithm - the 'felicific calculus' to estimate an action's merits according to the amount of pain or happiness they produced. Psychologists, later on, followed suit by maintaining that, if surveyed, anyone could rate their 'subjective happiness' meaningfully on a predetermined scale; medical scientists, also, strived to demonstrate that the 'state of mind' does have tangible effects on health indicators such as heart rate, blood pressure et cetera (Powdthavee, 2010).

These attempts were soon dismissed by economists as scientifically invalid, since, they argued, definitions of happiness or pain differ from person to person, making data incomparable. What economists did believe could be easier to estimate was instead tracking patterns of people's needs, tendencies and aspirations on the basis of the amount of money they would spend on them: this culminated in the works of Paul Samuelson, Simon Kuznets, Richard Stone, who, in the 1930s, created the national accounting systems which the GDP originates from (Fox, 2012). The GDP was then conceived as a mere mathematical indicator of market production and economic activity for policymakers' reference, but soon came to be used as a quasi-synonym of 'development' itself, in particular after it was embraced by newly established Bretton Woods' institutions such as the International Monetary Fund, in a context of intense economic reconstruction, liberalism and heightened consumerism.

The GDP is a certainly practical, straightforward single-figure index, which is relatively easy to quantify, but by no means perfect, and hardly suitable to gauge holistic wellbeing. This metric, for instance, does not capture the contribution of unpaid household work, volunteering activities, leisure or social relations, environmental degradation, nature's intrinsic values, resource depletion. It remains foreign to estimations of durability, sustainability, health, education, security or income inequality. In other words GDP, by definition, overlooks fundamental qualitative components of societal wellbeing. It can't reflect everything that matters, because it was actually never conceived to do so.

To compensate said shortcomings, distinct metrics of health, education, environmental impact and other non-market dimensions have also been created throughout time, but they have often lacked the popularity and 'appeal' of the highly manageable, easy-to-compare GDP. 
A notable turning point was in 1990 when Mahbub ul Haq and Amartya Sen (economists at the United Nations Development Programme) devised the Human Development Index (HDI), which for the first time brought together into a composite figure a range of both economic and non-economic dimensions of development, namely: education, health and living standard ${ }^{8}$.

Numerous similar initiatives and related composite indexes have since then emerged to attempt a comprehensive measurement of various components of socioeconomic development. For instance, the Stiglitz-Sen-Fitoussi Commission ${ }^{9}$ on the Measurement of Economic Development and Social Progress (Stiglitz et al., 2010; Institut National de la Statistique et des Etudes Economiques, 2010) launched in 2008 by French President Sarkozy, sparked an international debate which strongly influenced the subsequent adoption by the Organisation for Economic Cooperation and Development (OECD) of its 'Better Life Index', covering a combination of 11 domains ranging from 'housing' to 'civic engagement' to 'work-life balance'. The Legatum Prosperity Index of the UK-based Legatum Institute takes into consideration 89 variables across eight 'sub-indices ${ }^{10}$, while the Multidimensional Poverty Index (MPI) developed by the Oxford University's Initiative for Poverty and Human Development transcends the concept of poverty as merely income-centered, re-defining it as weighed average deprivations across ten key indicators in the same three dimensions (i.e. health, education and living standards) of the HDI.

The GNH Index - methodologically most influenced by the above mentioned MPI - should thus be seen as yet another example of this broad growing trend.

\section{The GNH Index}

During the process of reforms investing Bhutan's political life in the early 2000s, it appeared clear that if GNH was to realistically represent a practical tool shaping day-today policymaking, it had to be measurable. Only standardized, replicable methodologies producing objective numerical results, in fact, could allow meaningful evaluations, and even comparisons of development policy outcomes. Therefore, since

8 The health dimension is assessed by life expectancy at birth; the education dimension is measured by mean of years of schooling for adults aged 25 years and more, and expected years of schooling for children of school entering age. The standard of living dimension is measured by gross national income per capita.

${ }^{9}$ The Commission was chaired by Prof. Joseph Stiglitz, advised by Prof. Amartya Sen and coordinated by Prof. Jean-Paul Fitoussi.

${ }^{10}$ Namely: economy, entrepreneurship \& opportunity, governance, health, education, social capital, personal freedom, safety and security. 
2005 the Bhutanese government, through ad-hoc institutions such as the GNH Commission and the Centre for Bhutan Studies and GNH Research, focused its attention onto the very structuring of a rigorous system to survey its people, assess their levels of satisfaction, and ultimately produce a single-figure 'GNH Index'.

Based on Alkire-Foster multidimensional methodology (Alkire et al., 2002; 2009; 2011) ${ }^{11}$, the GNH Index consists of a weighted average gathered from 33 'cluster' indicators - both subjective and objective in nature, statistically reliable, relevant to and comprehensible by potential local respondents - across nine domains representing significant components of Bhutanese citizens' wellbeing, namely: psychological wellbeing; living standards, good governance; health, education; community vitality; cultural diversity and resilience; ecological diversity and resilience; and time use.

Domains are equally weighted, but the subjective and self-report-based indicators within them, though, carry, in general, lighter weights than the objective ones. 'Happiness' is defined as the achievement of 'sufficiency' in six of the nine domains, or, in other terms, by overall positive achievement in 66 percent of all weighted indicators. Such 'cutoff' delivers relevant quantitative outcomes, while still acknowledging that not all indicators are relevant to everyone in the same way.

The calculation undergoes two distinctive, subsequent procedures of 'identification' and 'aggregation'. The first reveals whether each household has attained sufficiency in each of the nine domains, and it is pursued by applying a sufficiency cutoff to every single indicator. Achievements exceeding the cutoff are replaced by the sufficiency levels themselves, so that they do not further affect the GNH Index score.

In the following 'aggregation' phase, data of the population are merged into a decomposable index that must be able to inspire policies that may increase the level of satisfaction both of 'happy' citizens and of those who aren't happy yet. The GNH Index looks straight at the very shortcomings of GNH implementation so that they are remedied, and the overall GNH improved, by 'subtracting' them from the ideal value of ' 1 '. The GNH Index is thus equal to 1 minus the product of two measures, ' $\mathrm{H}$ ' and 'A' $(\mathrm{GNH}=1-\mathrm{HA})$, where ' $\mathrm{H}$ ' is the headcount representing the percentage of people who do not enjoy sufficiency in six or more domains (obtained dividing the number of nonhappy people by the total number of respondents) and ' $\mathrm{A}$ ' is the average number of dimensions in which people are deprived (obtained dividing the number of insufficient indicators by the number of 'unhappy' people).

${ }^{11}$ The same at the very core of the Multidimensional Poverty Index (Alkire et al., 2002; 2009; 2011). 
Notes on Bhutan's Gross National Happiness and its Measurement

It is possible to break down the equation and obtain different values. For instance, the percentage of people who are happy would be given by $H_{h}=100 \%-H$.; similarly, the percentage of domains in which people who are not yet happy do enjoy sufficiency will be given by $A_{h}=100 \%-A \notin$. Additional cutoffs are selected to further differentiate among Bhutanese who are 'unhappy' (0-49.9\%), 'narrowly happy' (50-65.9\%), 'extensively happy' (66-76.9\%), or 'deeply happy' (77-100\%). Values can also be decomposed and evaluated by district, time frame, single domain, gender, occupation, level of education et cetera (Centre for Bhutan Studies and GNH Research, 2010; Ura et al., 2012a).

The advantages of this methodology are that it delivers a wide array of informative inputs for public policymaking, and it can coherently synthesize many different relevant phenomena in basic mathematical formulas. In addition, domains and indicators are chosen on the basis of their actual relevance to the local context; questionnaires are conceived to be understandable by their target audience; the calculation relies on a 'cutoff approach' which is purposefully focused on the middle tier of achievements that are relevant to the wellbeing of most people; the index can be broken down by groups, and performance patterns can be monitored in detail over time. Above all, this methodology highlights the very sections of the population which do not yet enjoy sufficient quality of life, setting therefore very concrete, people-centered objectives for the country's development governance agenda.

\section{The surveys}

After drawing on inputs from various relevant stakeholders and sections of the Bhutanese society, ranging from academics to administrators, to ordinary citizens from various settings and backgrounds, the Centre for Bhutan Studies and GNH Research produced a detailed questionnaire covering nine key areas crucially reflecting the principles of GNH.

A first pilot survey was conducted over a group of 350 respondents, in 2006. The pilot tested surveying methodologies and procedures, preparing the field for a further, more significant trial held in December 2007. Budget issues limited the survey to just 12 districts out of 20 , reaching a sample size of only 950 respondents, but the data analysis that followed was nonetheless useful to lead to the production of the GNH Index itself (2008).

A first, thoroughly improved national survey was commissioned by the Government in 2010, and carried out between the months of April and December of the 
same year by a total of fifty-five enumerators ${ }^{12}$, divided into five teams, each led by a 'field supervisor'.

The survey covered a sample of $7142^{13}$ respondents, considered nationally representative as it included respondents from different relevant walks of life in urban and rural settings.

The survey provided three orders of results: headcount, intensity and overall GNH Index. The 'headcount ${ }^{14}$, i.e. the percentage of people who are considered happy as they reach sufficiency levels in at least six or more of the nine domains, was 40.9 percent. The 'intensity' ${ }^{15}$, i.e. the average sufficiency enjoyed by the Bhutanese people, showed that 59.1 percent of Bhutanese who weren't happy yet lacked sufficiency in 43.4 percent of the domains (or, in other words, they reached sufficiency in $56.6 \%$ of the domains, not 66 percent required by the sufficiency cutoff). Hence, on average, notyet-happy Bhutanese lacked sufficiency in slightly less than four domains ${ }^{16}$, or, conversely, they enjoyed sufficiency in just over five domains. This determined an overall 'GNH Index' of $0.743^{17}$.

The adopted methodology allows for numerous 'multidimensional breakdowns' of the survey's overall data, providing precious information to policymakers on the very 'quality' of the results.

For instance, all nine domains contributed to happiness to some extent, but the ones that contributed to the GNH Index the most (or, in other words, the ones in which Bhutanese displayed the most sufficiency) were health (14\%), ecology, psychological wellbeing, and community vitality $(12 \%$ each), while the least contributing were educational background or good governance $(9 \%$ each) (Centre for Bhutan Studies and GNH Research, 2010; Ura et al., 2012a).

\footnotetext{
12 The Centre for Bhutan Studies and GNH Research trained appointed enumerators paying particular attention to proper translation techniques of the questionnaire from English into Dzongkha and other local dialects (Ura et al., 2012).

${ }^{13}$ Within this sample, 6476 questionnaires $(90.7 \%)$ were, in the end, considered fully valid and hence used for calculation (Ura et al., 2012a)

${ }^{14} H_{h}=100 \%-H$.

${ }^{15} A_{h}=100 \%-A$.

${ }^{16}$ Nine domains times $0.43=3.87$.

17 Ranging from 0 to 1 , the higher the number, the better. GNH Index $=1-H A$, where " $H$ " is the headcount representing the percentage of people who do not enjoy sufficiency in six or more domains and " $A$ " is the average number of dimensions in which people are deprived, hence: $1-(0.591 \times 0,434)=1$ $0.2564=0.743$ (Ura et al. 2012a).
} 
Notes on Bhutan’s Gross National Happiness and its Measurement

Substantial equality was registered across administrative districts or dzongkhags ${ }^{18}$, but GNH rankings of dzongkhags would not necessarily reflect income rankings: the richest dzongkhag - Thimphu, the capital - in terms of income per capita was not the happiest, while income-poor Sarpang, Dagana, Zhemgang for example, scored rather high GNH results (Ura et al. 2012a).

In cities, 50 percent of people appeared to be happy, as opposed to only 36 percent of happy people in rural areas; the composition of happiness also differed between urban and rural populations, as community vitality, cultural diversity and good governance contributed more to happiness in rural areas, while living standards, education and health contribute more to happiness in urban areas; city dwellers displayed insufficiency in governance, time use and culture, whereas in rural areas insufficiency was highest in education and living standards.

When data are analyzed gender-wise, men appear far happier than women (49\% of men versus only $33 \%$ of women); while both genders fared similarly in regards to health, time use, governance, and culture. Women did seem to achieve higher satisfaction in living standards and ecology, whereas men did so in education, community vitality and psychological wellbeing.

As far as educational levels are concerned, primary education seemed to make a difference, making people far happier than those with no formal education ${ }^{19}$, but further educational attainment did not seem to significantly affect GNH levels; still, across groups with higher education the contribution to happiness of indicators such as living standards and education would increase, while that of governance and culture decrease (Ura et al. 2012b).

The scope of multidimensional analyses of these data appears virtually unlimited. While the methodological 'technicalities' of GNH measurements may certainly be further debated and adjusted, it is safe to conclude that the above mentioned aggregate measures and all the inputs which, once decomposed, they can provide, already constitute the relevant product of a valid, comprehensive, 'refreshing' people-centered assessment of progress.

The significance of this paradigmatic change of perspective lies precisely in the ability to deliver a variety of precious inputs that simply transcend the mere quantitative dimension and the debate over the subjective or objective nature of its

${ }^{18}$ Even if margins of difference are slim, the happiest dzongkhags include Paro, Sarpang, Dagana, Haa, Thimphu, Gasa, Tsirang, Punakha, Zhemgang, and Chukha, while the least happy was the dzongkhag of Samdrup Jonkhar (Ura et al. 2012).

${ }^{19} 90$ percent of unhappy people have no formal education (Ura et al., 2012b). 
Notes on Bhutan’s Gross National Happiness and its Measurement

components. This approach provides policymakers with 'unfiltered' access into people's perceptions of governance as well as into actual policy outcomes, thus helping streamline goals, prioritize targets and allocate resources. More profoundly, it (re)defines, with extreme clarity, the very scope and aim of any government's pursuit of truly holistic and sustainable socio-economic development.

\section{Preliminary results of the 2015 Survey}

The preliminary results of the latest GNH Survey 2015 were shared with attendees (among whom, the author of this paper) of the International Conference on Gross National Happiness ('From GNH Philosophy to Praxis and Policy') held in Paro, Bhutan, between November 3 and November 6, 2015.

The respondents of the 2015 Survey were 7153 . The percentage of Bhutanese who can be defined as 'happy' is 43 percent, up from 41 percent in 2010 . The overall GNH Index 2015 is expected has increased to 0.756 from 2010's 0.743. Drivers of growth are identified in improved living standards, service delivery, health, and participation in cultural activities. Significant reductions in sufficiency levels have, instead, been registered in the domains of cultural diversity, community vitality and psychological wellbeing.

Preliminary analyses of data breakdowns seem to confirm some of the key trends identified in the 2010 Survey. The gender gap, although narrowing, still persists, as 51 percent of men are happy versus 39 percent of women. So does the rural-urban divide: despite increases in both areas, 55 percent of urban dwellers are happy versus 38 percent of rural inhabitants. Districts' income rankings once again do not mirror GNH rankings. Besides Thimphu, less wealthy districts such as Gasa, Paro, Bhumthang also feature among the happiest districts in the country (Centre for Bhutan Studies and GNH Research, 2015; Ura et al., 2015).

\section{Conclusion}

Gross National Happiness per se, to its full extent, is a distinctively Bhutanese phenomenon. Over the centuries, persistent animist traditions as well as pervasive Vajrayana Tantric Buddhist beliefs have infused the Bhutanese society with a profound awareness of the essential interdependence among universe's key components ecological, spiritual, social, political, economic - and a unique proclivity for equitable, 'balanced living', which are at the very core of GNH as a development policy.

The very early stage of development combined with the country's geographical remoteness, history of isolation, peculiar cultural identity as well as a small, mostly 
rural population unevenly distributed across the national territory are all highly conducive conditions towards the pursuit of a rather uncharted development path.

Nevertheless, GNH's broad significances aren't irrelevant to the rest of the world. They are actually quite universal, and already resonating in many similar initiatives undertaken by multilateral institutions such as the UN (e.g. Sustainable Development Goals, 'March 20 International Happiness Day'), the European Union (e.g. 'Beyond the GDP' Initiative), the OECD (e.g. 'Measuring what Matters' Initiative), and, increasingly, by governments of both developing and developed countries across the globe.

The recent concrete attempts to 'operationalize' GNH and standardize its measurement are also reflected in growingly popular methodologies and metrics ranging from UN's Human Development Index to Oxford University's Multidimensional Poverty Index, OECD's Better Life Index, or the Legatum Prosperity Index, just to name a few.

Human beings are multidimensional, so are their needs, aspirations and challenges. Reducing development - an equally multidimensional concept - to a merely economic endeavor is, at best, simplistic and limited. In fact, individuals and their collective configurations - i.e. societies - naturally aim at pursuing their own far more complex, comprehensive 'wellbeing'.

Wellbeing is indeed hard to define, measure and achieve, but these difficulties should not deter from its higher pursuit. This calls political leaders and the societies that are often supposed to select and scrutinize them to a more taxing duty, which, in Bhutan or elsewhere, may also ultimately deliver inclusive development and truly sustainable solutions to the steep, interconnected challenges of modern times.

\section{References}

Alkire, S. (2002). Dimensions of human development. World Development, 30(2):181205.

Alkire, S. (2008). Choosing dimensions: The capability approach and multidimensional poverty. In N. Kakwani \& J. Silber (eds.), The Many Dimensions of Poverty, Palgrave, NY.

Alkire, S. and Foster, J.E. (2011). Counting and multidimensional poverty measurement, Journal of Public Economics, 95(7-8).

Centre for Bhutan Studies and GNH Research (2010). Gross National Happiness Index \& Survey 2010 Report, Thimphu. 
Centre for Bhutan Studies and GNH Research(GNHC) (November 3, 2015).[Press Release], Paro, Bhutan, Retrieved December 17, 2015, from: http://www.bhutanstudies.org.bt/conferences/2015-gnh-conference/day-2/

Constitution of the Kingdom of Bhutan. (2008). Retrieved December 15, 2015, from http://www.bhutanaudit.gov.bt/About\%20Us/Mandates/Constitution\%20of\%20 Bhutan\%202008.pdf

Fox, J. (2012). The economics of well-being. Harvard Business Review, Jan-Feb.

Gross Happiness Commission (GNHC). (n.d.). Gross National Happiness. Retrieved December 12, 2015, from http://www.gnhc.gov.bt/mandate/, http://www.gnhc.gov.bt/wp-content/uploads/2011/04/11-

FiveYearPlan.pdfInstitut National de la Statistique et des Etudes Economiques, INSEE, . (n.d.). Documents du site de la "Commission sur la Mesure de la Performance Économique et du Progrès Social". Retrieved December 2015, from http://www.insee.fr/fr/publications-etservices/default.asp?page=dossiers_web/stiglitz/documents-commission.htm

Legathum Institute. (2015). The Legathum Prosperity Index. Retrieved December 15, 2015, from https://lif.blob.core.windows.net/lif/docs/defaultsource/publications/2015-legatum-prosperity-index-pdf.pdf?sfvrsn=2

Ministry of Agriculture and Forests. (2015, June 26). 600th Community Forest handed over. Retrieved December 13, 2015, from http://www.moaf.gov.bt/600thcommunity-forest-handed-over/

Ministry of Labor and Human Resources, Government of Bhutan. (2013). Labor market information bulletin. Retrieved December 25, 2015, from http://www.molhr.gov.bt/molhr/wp-content/uploads/2015/07/Final-draftLabour-Market-Information-Bulletin-2014-1.pdf

Organization for Economic Co-operation and Development(OECD). (2015). OECD Better Life Index. Retrieved December 2015, from http://www.oecd.org/statistics/datalab/bli.htm

Oxford Poverty and Human Development Initiative, Oxford University (n.d). Retrieved December 2015, from OPHI: http://www.ophi.org.uk/

Powdthavee, N. (2010). The happiness equation. London: Icon Books. .

Tobgay,T. (2015). 2015 GNH Conference [Key note speech by Honourable Prime Minister of Bhutan, Lyonchoen Tsering Tobgay], International Conference on Gross National Happiness, Retrieved December 12, 2015 from: http://www.bhutanstudies.org.bt/conferences/2015-gnh-conference/

Samuelson, P. A. (1954). The pure theory of public expenditure, Review of Economics and Statistics, 36 (4): 387-389. 
Notes on Bhutan’s Gross National Happiness and its Measurement

Samuelson, P. A. (1983). Foundations of economic analysis, Cambridge, MA: Harvard University Press.

Stiglitz, J.E., Sen, A., Fitoussi, J.P. (2010). Mismeasuring our lives: Why GDP doesn't add up?, New York: The New Press.

Stone, R., Stone, G. (1961). National income and expenditure, London: Bowes \& Bowes.

United Nations [UN]. (2015, December 10). List of least developed countries. Retrieved December 18, 2015, from United Nations: http://www.un.org/en/development/desa/policy/cdp/ldc/ldc_list.pdf

United Nations Development Programme [UNDP]. (2015). Human development report 2015. New York: UNDP.

UNHCR: The UN Refugee Agency. (2015, November 19). Retrieved December 12, 2015, from Resettlement of Bhutanese refugees surpasses 100,000 mark: http://www.unhcr.org/564dded46.html

World Bank(2015b). Poverty headcount ratio at national poverty lines (\% of population). Retrieved December 20, 2015, from World Bank Group: http://data.worldbank.org/indicator/SI.POV.NAHC

World Bank(2015a). GDP per capita. Retrieved December 18, 2015, from World Bank Group: http://data.worldbank.org/indicator/NY.GDP.PCAP.CD

Ura, K., Alkire, S., Zangmo, T., Wangdi, K. (2012a). A short guide to gross national happiness index, The Centre for Bhutan Studies and GNH Research, Thimphu.

Ura, K., Alkire, S., Zangmo, T., Wangdi, K. (2012b). An extensive analysis of GNH index, Thimphu.

Ura, K., Alkire, S., Zangmo, T., Wangdi, K. (2015). Provisional findings of 2015 survey, Thimphu. 